\title{
Spatial and temporal variability in nitrogenase activity and diazotrophic community composition in coastal microbial mats
}

\author{
Ina Severin ${ }^{1}$, Lucas J. Stal ${ }^{1,2, *}$ \\ ${ }^{1}$ Department of Marine Microbiology, Netherlands Institute of Ecology, NIOO-KNAW, PO Box 140, 4400 AC Yerseke, \\ The Netherlands \\ ${ }^{2}$ Department of Aquatic Microbiology, Institute of Biodiversity and Ecosystem Dynamics, University of Amsterdam, \\ PO Box 94062, 1090 GB Amsterdam, The Netherlands
}

\begin{abstract}
Coastal microbial mats are highly diverse micro-scale ecosystems in an environment characterized by strongly fluctuating conditions. Nitrogen $(\mathrm{N})$ fixation is an important process in these often $\mathrm{N}$-limited ecosystems. We investigated the characteristics of $\mathrm{N}_{2}$ fixation and the composition of the $\mathrm{N}_{2}$-fixing (diazotrophic) community in 3 microbial mats situated along an intertidal gradient over a period of 3 yr by using the acetylene reduction assay and by analyzing more than 800 environmental nifH sequences. In 2008, nitrogenase activity (NA) in the 3 mat types differed with respect to the daily pattern and daily integrated rates (ranging from 5 to almost $150 \mathrm{mmol} \mathrm{C}_{2} \mathrm{H}_{4} \mathrm{~m}^{-2} \mathrm{~d}^{-1}$ ). The diazotrophic community composition in the 3 mat types was also dissimilar. The nif $H$ clone libraries at the location that was most influenced by freshwater contained mostly cyanobacterial and alphaproteobacterial sequences, whereas the other 2 locations were dominated by gamma- and deltaproteobacterial diazotrophs. These differences were attributed to the specific environmental conditions at each location resulting from their position along the intertidal gradient and likely caused the differences in the recorded patterns of $\mathrm{N}_{2}$ fixation. Moreover, in each of the mat types, a dramatic shift in the diazotrophic community was observed over a period of 2 to 3 yr. These shifts varied greatly between the locations. The characteristics of NA at the same location in different years also varied considerably. $\mathrm{N}_{2}$ fixation in these microbial mats was spatially and temporally variable, which was attributed to the shifts in diazotrophic community composition along the littoral gradient and during the $3 \mathrm{yr}$ of investigation.
\end{abstract}

KEY WORDS: Microbial mats · Nitrogenase activity $\cdot$ Diazotrophic community

\section{INTRODUCTION}

Microbial mats are benthic communities of microorganisms, usually dominated by phototrophic bacteria (e.g. Krumbein et al. 1977, Jørgensen et al. 1983). They develop as vertically stratified populations of functionally different groups of microorganisms along physicochemical gradients. This stratification has been attributed to the prevailing gradients of oxygen, sulfide and light, which are generated and maintained by the metabolic activities of the community members (Revsbech et al. 1983, van Gemerden 1993). Microbial mats are distributed globally and can be found in a wide variety of environments, such as cold polar regions, dry and hot deserts, hypersaline environments, hot springs and coastal environments. The latter are often characterized by strongly fluctuating environmental conditions, such as large variations in water availability and desiccation as well as salinity, temperature, oxygen, and sulfide gradients. They are also often depleted of combined N, which limits primary productivity (Paerl 1990).

In most cases, phototrophs, such as diatoms and Cyanobacteria, form the main structural element of microbial mats. As the primary colonizers on bare substrate, Cyanobacteria are the prerequisite for the 
development of this microbial ecosystem. The ability to fix atmospheric $\mathrm{N}_{2}$ (dinitrogen) represents a distinct advantage that allows diazotrophic Cyanobacteria to colonize the often nutrient-poor and particularly $\mathrm{N}$-depleted environments in which microbial mats thrive. However, the ability to fix $\mathrm{N}_{2}$ is also widespread among other Bacteria and Archaea. Therefore, investigating the entire bacterial community of potential $\mathrm{N}_{2}$-fixing organisms (diazotrophs) is essential to explain the characteristics of $\mathrm{N}_{2}$ fixation in microbial mats. This can be done by detecting and characterizing $n i f H$, the gene coding for the Fe protein of nitrogenase, the enzyme complex which catalyzes the reduction of atmospheric $\mathrm{N}_{2}$ to ammonia. NifH has been shown to be phylogenetically informative and thus to allow the distinction between Cyanobacteria and other Bacteria and Archaea, as well as between heterocystous and non-heterocystous Cyanobacteria (BenPorath \& Zehr 1994). Previous analyses of nifH from the environment demonstrated that microbial mats contain a diverse diazotrophic community (e.g. BenPorath \& Zehr 1994, Olson et al. 1999).

For some microbial mats it has been shown that the community structure varies depending on the location of the mats along an intertidal gradient (Rothrock \& Garcia-Pichel 2005, Dijkman et al. 2010). In these studies, the clear difference between the communities of different microbial mats was attributed to a difference in desiccation frequency. However, several other factors including temperature, sedimentation patterns, oxygen concentration and oxygen penetration depth could also be responsible for changes in the community composition. Studies on the shifts of the diazotrophic fraction of the microbial community along environmental gradients are rare. However, some studies demonstrated temporal variations in daily $\mathrm{N}_{2}$ fixation pattern and rates (e.g. Joye \& Paerl 1994) as well as differences in the nifH gene pool in summer and winter (Zehr et al. 1995, Paerl et al. 1996). These differences were attributed to changing environmental conditions supporting growth and activity of different types of diazotrophs in different seasons. In a changing environment, it may also be possible to find differences in the daily $\mathrm{N}_{2}$ fixation pattern between different years, when the diazotrophic community has changed due to altered environmental conditions.

The aim of this study was to investigate the differences in diazotrophic community composition and $\mathrm{N}_{2}$ fixation in 3 microbial mats situated along an intertidal gradient by using the acetylene reduction assay and by analyzing more than 800 environmental nifH sequences. We also followed shifts in the diazotrophic community composition as well as differences in the daily $\mathrm{N}_{2}$ fixation pattern over a period of $3 \mathrm{yr}$.

\section{MATERIALS AND METHODS}

Sampling. The study site was located on the Dutch barrier island Schiermonnikoog (Fig. 1). The geographic coordinates of the study site were $53^{\circ} 29^{\prime} \mathrm{N}$ and $6^{\circ} 08^{\prime} \mathrm{E}$. Microbial mats were found at the sandy beach covering the north-western bank of the island facing the North Sea. Areas of the beach are currently turning into a salt marsh, resulting in mats partly overgrown by higher plants. Due to this succession and the gradually changing influence of the North Sea, different mat types developed along the littoral gradient.

The microbial mats on Schiermonnikoog are subjected to a regular tidal cycle. The duration and amplitude of the flooding depend on the location. In 2006, 2 sampling sites were chosen based on microscopic observations of the cyanobacterial community composition as well as their location along the littoral gradient (Severin \& Stal 2008). Stn I was located near the dunes and influenced by both seawater and freshwater (rain and upwelling groundwater). This area was only irregularly inundated by the sea, usually at spring tide and with northerly winds. Salt marsh plants grew in the surrounding areas of the mats but did not cover the mats themselves. Microscopic analysis of the mats at Stn I revealed high cyanobacterial species diversity containing both heterocystous and non-heterocystous filamentous Cyanobacteria as well as unicellular types. Stn II was situated near the low water mark. Due to tidal inundation, seawater was far more important than the occasional rain showers at this station and this distinguished it from Stn I. This station was completely covered with seawater every $12 \mathrm{~h}$. No salt marsh plants covered this area of the beach and no other vegetation was observed at this sampling site. The Cyanobacteria at Stn II were mostly non-heterocystous forms, predominantly Lyngbya aestuarii. Some heterocystous Cyanobacteria were observed, but these organisms did not seem to be a structural part of the Stn II community. Stn I was sampled again in 2007. Additionally, a third station (Stn III) was chosen and sampled in 2007. Stn III was located between Stns I and II and therefore represented an area influenced by both seawater and freshwater in varying proportions, depending on the tidal amplitude. At high tide, sea water reached the sampling site but the duration of flooding and the water height were considerably lower than at Stn II. At Stn III salt marsh plants were partly overgrowing the established mats. A dense vegetation of salt marsh plants prevented the establishment of microbial mats so that the sampling area was chosen outside the vegetated patches. Based on microscopic observation, Microcoleus chthonoplastes was identified as the dominant cyanobacterial component. A variety of other non-heterocystous and heterocystous 


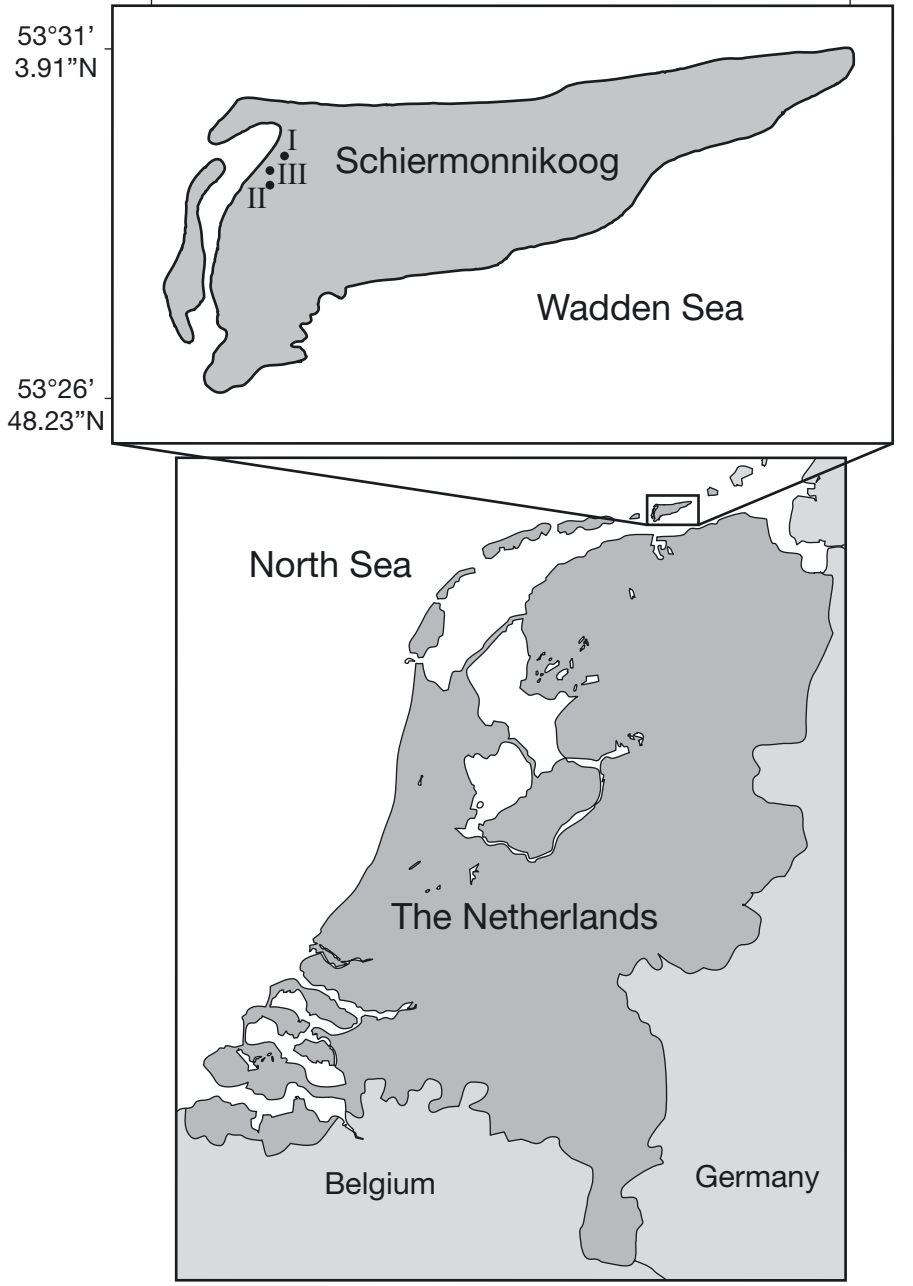

Fig. 1. Stns I, II and III on the island Schiermonnikoog

species were found as well. All 3 stations were sampled in 2008.

For each $24 \mathrm{~h}$ measurement of nitrogenase activity (NA), samples of the mats were collected using a corer with a diameter of $50 \mathrm{~mm}$ made of a PVC tube. In 2006, NA was measured every hour. In 2007 and 2008, samples were taken every 2 and $4 \mathrm{~h}$, respectively. NA was measured once per station in 2006 and 2007 and on 2 consecutive days in 2008. The upper 2 to $3 \mathrm{~mm}$ of the mat was dissected using a knife. After finishing the NA measurements, the sample was frozen in liquid nitrogen and stored at $-80^{\circ} \mathrm{C}$ for later chlorophyll determination. Samples for molecular analyses were collected by using disposable $10 \mathrm{ml}$ syringes of which the needle connector was cut off to obtain a corer with a diameter of $1.5 \mathrm{~cm}$. The top $2-3 \mathrm{~mm}$ of the mat was sampled and sectioned in 4 equal parts using a scalpel. Each part was transferred into a separate cryovial (Simport Plastics) and immediately frozen in liquid nitrogen.
Nitrogenase activity. NA was measured using the acetylene reduction assay (ARA) (Hardy et al. 1968). The upper 2 to $3 \mathrm{~mm}$ of the mat was placed in a custom-made measuring cell (Staal et al. 2001) with a diameter of $46 \mathrm{~mm}$ and moisturized with filtered (Whatman GF/F glass microfiber filter) North Sea water. All mat samples were incubated simultaneously under exactly the same temperature (thermostat circulating water bath) and ambient light conditions by using a set-up with 6 measuring cells. NA measurements were carried out every $4 \mathrm{~h}$. At each of the time points, $2 \mathrm{ml}$ acetylene with a known background concentration of ethylene (Messer) were injected. Incubations lasted $1 \mathrm{~h}$ after which $10 \mathrm{ml}$ of the headspace gas was transferred into evacuated and sealed $10 \mathrm{ml}$ crimp top vials (Chrompack-Varian). Between the incubations, air was flushed through the measuring cells using an air pump. Acetylene and ethylene concentrations were measured using a gas chromatograph (Chrompack CP 9001) equipped with a flame ionization detector. The temperatures of injector, detector and oven were 90,120 and $55^{\circ} \mathrm{C}$, respectively. Helium was used as carrier gas at a flow rate of $10 \mathrm{ml} \mathrm{min}^{-1}$. The supply rates of $\mathrm{H}_{2}$ and clinical air for the flame ion-

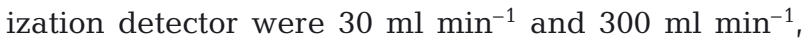
respectively. Gases were purchased from Westfalen Gassen. The column was a $25 \mathrm{~m}$ long wide-bore silica fuse column (inner diameter $0.53 \mathrm{~mm}$ ) packed with Poropak U (Chrompack-Varian). Ethylene production was calculated according to Stal (1988) by using acetylene as an internal standard and correcting for the ethylene present as contaminant in the acetylene.

The characteristics of NA for each mat type and year can be derived from the light response curves (Staal et al. 2002). Based on the light response curves recorded for the mats at all 3 stations in 2006 and 2007 (Severin \& Stal 2008, 2010), potential NAs for the 2008 mats were calculated using the light intensities recorded during the incubations in 2008. Because light intensity is commonly assumed to be one of the major factors controlling NA, we aimed at excluding this factor by comparing all daily cycles based on exactly the same light intensities (recorded in 2008). If the NA characteristics (i.e. the light response curves) were different for the $3 \mathrm{yr}$, the calculation based on the same light intensities should result in dissimilar daily NA patterns and daily integrated rates. NA rates were integrated for a period of $24 \mathrm{~h}$ to compare daily rates among $3 \mathrm{sta}-$ tions for $1 \mathrm{yr}$ and among years for 2 stations.

Monitoring nitrogenase activity. In order to evaluate the influence of the environmental parameters light, temperature and tidal cycle on NA, samples were taken twice a day at 10:00 $\mathrm{h}$ and 22:00 h. The top 2 to $3 \mathrm{~mm}$ of the mat samples was incubated in $30 \mathrm{ml}$ serum flasks which were sealed with a butyl rubber stopper 
(Rubber). To each of the samples, $2 \mathrm{ml}$ of filtered seawater (tidal floodwater) from the sampling location were added. Samples of all 3 mat types were incubated in duplicate. The vials were closed and $5 \mathrm{ml}$ acetylene (Messer) was injected. The gas phase was mixed by pumping with the syringe and $5 \mathrm{ml}$ of the headspace was removed to maintain normal pressure. Incubations lasted $3 \mathrm{~h}$ after which $5 \mathrm{ml}$ of the headspace gas was transferred into evacuated and sealed $5 \mathrm{ml}$ crimp top vials (Chrompack-Varian). Acetylene and ethylene concentrations were measured by gas chromatography. Natural photon flux density (PFD, $\mu m o l \mathrm{~m}^{-2} \mathrm{~s}^{-1}$ ) was recorded continuously using a photosynthetic active radiation (PAR) light sensor (LI-190 Quantum Sensor) connected to a data logger (Licor 1000). The PFD was measured at intervals of $1 \mathrm{~s}$ and averages were stored every minute. Temperature was recorded at the surface of the mat at the time of sampling. The tidal cycle was reconstructed based on publicly available information provided by the Dutch Ministry of Transport, Public Works and Water Management (Ministerie van Verkeer en Waterstaat, www.getij.nl).

Statistical analyses. The influence of the variation in the variables tide, light and temperature on the variation in NA was tested with 1-way ANOVA using the SPSS software program version 17.0.

Nucleic acid extraction. DNA from all stations was extracted in triplicates with the MO BIO UltraClean Soil DNA Isolation Kit (MO BIO Laboratories) according to the manufacturer's protocol. Quality and quantity of extracted DNA was checked on a $1 \%$ agarose gel and with the NanoDrop ND 1000 (NanoDrop Technologies). The extracts from each station were combined and immediately used for amplification.

PCR, cloning and sequencing. For the amplification of nifH, a nested PCR with the internal primer pair nifH 1 (5' TGY GAY CCN AAR GCN GA 3') and nifH 2 (5' ADN GCC ATC ATY TCN C 3') (Zehr \& McReynolds 1989) and the external primers nifH 3 (5'ATR TTR TTNGCNGCRTA $3^{\prime}$ ) and nifH 4 (5'TTYTAYGGN AAR GGN GG 3') was performed (Zani et al. 2000). For the first amplification with primers nifH 3 and nifH 4 , each $25 \mu \mathrm{l}$ PCR reaction mix contained $25 \mathrm{pmol}$ of each primer, $0.2 \mathrm{mM}$ deoxynucleoside triphosphates (dNTPs), $1 \times$ reaction buffer and $0.625 \mathrm{U}$ Qiagen HotStarTaq as well as 10 to $15 \mathrm{ng}$ DNA. For the nested reaction, $2 \mu \mathrm{l}$ of the PCR product from the first reaction was used as a template. Cycling conditions for both PCR-steps included $94^{\circ} \mathrm{C}$ for $15 \mathrm{~min}, 35$ cycles of $94^{\circ} \mathrm{C}$ for $1 \mathrm{~min}, 54^{\circ} \mathrm{C}$ (first reaction) or $57^{\circ} \mathrm{C}$ (nested reaction) for $1 \mathrm{~min}$ and $72^{\circ} \mathrm{C}$ for $1 \mathrm{~min}$, followed by an extension period of $72^{\circ} \mathrm{C}$ for $10 \mathrm{~min}$. The $359 \mathrm{bp}$ PCR products were checked on a $1 \%$ agarose gel.

The fresh PCR product was cloned using the TOPO TA Cloning Kit for Sequencing (Invitrogen) following the manufacturer's instructions. 192 clones and 96 clones per location were picked in 2006 and 2007-2008, respectively, and used for amplification with the M13primer pair (F: 5' GTA AAA CGA CGG CCA G 3' and R: 5' CAG GAA ACA GCT ATG AC 3') and checked by gel electrophoresis. Cycling conditions were $95^{\circ} \mathrm{C}$ for $2 \mathrm{~min}$, followed by 40 cycles of $94^{\circ} \mathrm{C}$ for $1 \mathrm{~min}, 55^{\circ} \mathrm{C}$ for $1 \mathrm{~min}, 72^{\circ} \mathrm{C}$ for $2 \mathrm{~min}$, and a final extension step at $72^{\circ} \mathrm{C}$ for $19 \mathrm{~min}$. PCR products were purified with the Sephadex G-50 Superfine-powder (GE Healthcare Bio-Sciences) and $45 \mu \mathrm{l}$ Millipore MultiScreen-plates. After determining the quantity of the purified PCR product, a sequencing reaction was performed for all positive amplification products using the BigDye Terminator chemistry (BigDye Terminator v3.1 Cycle Sequencing Kit, Applied Biosystems) and the M13 reverse primer.

Sequence analysis. Sequences were aligned in BioEdit (Ibis Biosciences), corrected by manual inspection and analysed for similarity in BLASTn (Basic Local Alignment Search Tool, National Center for Biotechnology Information). Similarities of the nucleotide sequences of environmental nifH clones and reference sequences are given in Table 1. In order to investigate the diversity of diazotrophs within one station as well as to compare the diversity among stations, alpha- and beta-diversity at all stations were estimated using the DOTUR and SONS software programs (Schloss \& Handelsman 2005, 2006) based on the alignment files for the nifH clone libraries. Clustering analysis (unweighted pair-group averages and the Euclidean distance measure, STATISTICA software package version 9, StatSoft) of annual data from each station was performed based on a similarity matrix including presence and absence of operational taxonomic units (OTUs) as well the number of sequences contained in these OTUs. A cut-off of $99 \%$ nucleotide sequence similarity was used to define an OTU.

All sequences are deposited at the NCBI GenBank database under the accession numbers GU193157 to GU193975.

\section{RESULTS}

\section{Spatial variability in nitrogenase activity}

The dynamics of the daily integrated NA for the 3 stations sampled in 2008 were measured using ARA. These are depicted in Fig. 2 together with the daily light records.

For Stn I, ethylene production ranged from 430 to $2680 \mu \mathrm{mol} \mathrm{m}^{-2} \mathrm{~h}^{-1}$ (Fig. 2A). The daily pattern of NA was slightly different for the $2 \mathrm{~d}$ on which measurements were made. On Day 1, NA decreased towards the evening, increasing slightly at sunset before falling 
Table 1. Reference sequences (as in NCBI GenBank database) most closely related to most common environmental nifH sequences derived from Stns I, II and III in 2006, 2007 and 2008 (pooled across stations and years)

\begin{tabular}{|c|c|c|}
\hline Phylogenetic affiliation & Species & $\begin{array}{c}\text { Sequence } \\
\text { similarity (\%) }\end{array}$ \\
\hline \multicolumn{3}{|l|}{ Presumed Cyanobacteria } \\
\hline \multirow[t]{4}{*}{ Oscillatoriales } & Lyngbya aestuarii & $94-99$ \\
\hline & Oscillatoria sp. & 88 \\
\hline & Oscillatoria sancta & 96 \\
\hline & Phormidium sp. & $85-90$ \\
\hline \multirow[t]{2}{*}{ Nostocales } & Anabaena sphaerica & 93 \\
\hline & Anabaena variabilis & $84-86$ \\
\hline \multirow[t]{2}{*}{ Chroococcales } & Cyanothece sp. & 81 \\
\hline & Gloeothece sp. & $83-84$ \\
\hline \multicolumn{3}{|l|}{ Presumed Proteobacteria } \\
\hline \multirow[t]{5}{*}{ Alphaproteobacteria } & Agrobacterium tumefaciens & $86-87$ \\
\hline & Azospirillum brasiliense & $86-90$ \\
\hline & Bradyrhiziobium japonicum & $80-85$ \\
\hline & Rhosospirillum rubrum & 89 \\
\hline & Rhodovulum spp. & $89-90$ \\
\hline \multirow[t]{2}{*}{ Betaproteobacteria } & Azoarcus communis & $84-89$ \\
\hline & Burkholderia xenovorans & 81 \\
\hline \multirow[t]{2}{*}{ Deltaproteobacteria } & Desulfovibrio spp. & $80-92$ \\
\hline & Geoalkalibacter ferrihydricus & $81-84$ \\
\hline \multirow[t]{13}{*}{ Gammaproteobacteria } & Acinetobacter sp. & 86 \\
\hline & Aeromonas sp. & 83 \\
\hline & Allochromatium minutissimum & $83-96$ \\
\hline & Azotobacter chroococcum & $84-85$ \\
\hline & Azotobacter vinelandii & 83 \\
\hline & Ectothiorhodospira shaposhnikovii & $82-88$ \\
\hline & Ectothiorhodospira mobilis & $82-86$ \\
\hline & Halorhodospira halophila & 85 \\
\hline & Klebsiella pneumoniae & 80 \\
\hline & Pseudomonas azotifigens & $85-87$ \\
\hline & Pseudomonas stutzeri & $86-90$ \\
\hline & Thiocapsa bogorovii & $83-90$ \\
\hline & Thiorhodospira sibirica & $81-83$ \\
\hline
\end{tabular}

Days $1 \& 2$, respectively. NA at Stn III also showed enhanced NA at sunrise ( 07:00-9:00 h; Fig. 2C). No increased activity was observed around sunset. The sunrise maximum was $627 \mu \mathrm{mol}$ $\mathrm{C}_{2} \mathrm{H}_{4} \mathrm{~m}^{-2} \mathrm{~h}^{-1}$ and therefore was one order of magnitude lower than at the other stations. Daily integrated NA was $\sim 5000 \mu \mathrm{mol} \mathrm{C}_{2} \mathrm{H}_{4} \mathrm{~m}^{-2} \mathrm{~d}^{-1}$ on both days.

\section{Factors influencing nitrogenase activity}

We tested to what extent variations in the tidal amplitude, light and temperature conditions explained variations in NA in 2008 (Tables 2 \& 3).

Based on 1-way ANOVA, $56 \%$ of the variation in NA at Stn I could be explained by recorded variations in light $(27 \%, p=0.006)$ and temperature $(29 \%$, $\mathrm{p}=0.007)$. Variations in the tidal amplitude, i.e. the coverage with seawater, did not play a role. At Stn II, only light conditions seemed to influence NA (12\% of the variation in AN explained by variation in light) but the result was not significant $(\mathrm{p}=0.055)$. None of the investigated factors could explain any of the NA-variations at Stn III.

\section{Temporal variability in nitrogenase activity}

The daily cycle of NA for all 3 mats was also calculated based on the light response curves generated in 2006

to minimum levels at night. At sunrise ( 06:00 h), NA started to increase and peaked in the morning ( 10:00 h). On Day 2, NA was highest in the afternoon ( 14:00-16:00 h) and decreased thereafter, reaching a minimum just before midnight. Some increase of NA was observed in the early morning before sunrise ( 04:00 h). Daily integrated NA at Stn I was 25747 and $23321 \mu \mathrm{mol} \mathrm{C} \mathrm{H}_{4} \mathrm{~m}^{-2} \mathrm{~d}^{-1}$ on Days $1 \& 2$, respectively. The daily NA cycle differed between Stns I and II. At Stn II, NA showed 2 clear peaks at about sunrise and sunset ( 08:00-09:00 and 22:00-23:00 h) on both days (Fig. 2B). Activity during the sunrise peaks was higher than at sunset. Total NA ranged from virtually zero at night to $14631 \mathrm{mmol} \mathrm{m}^{-2} \mathrm{~h}^{-1}$ during the sunrise peak on Day 1. Integrated for an entire day, NA reached 147249 and $113188 \mu \mathrm{mol} \mathrm{C}_{2} \mathrm{H}_{4} \mathrm{~m}^{-2} \mathrm{~d}^{-1}$ on
(Stns I and II) and 2007 (Stns I and III) and the light intensities measured in 2008. For all 3 stations, calculated NA (Fig. 3) did not agree with the actual measurements in 2008 (Fig. 2).

At Stn I, the daily NA cycle calculated from light response curves of 2006 show enhanced NA at sunset and sunrise (Fig. 3A). Calculated NA was generally higher at night whereas the opposite was the case for NA measured in 2008. Calculations based on light response curves from 2007 predicted a pattern of NA which was similar to the 2006 pattern at night but showed higher daytime activity. NA rates, however, were lower in 2007 compared to both 2006 and 2008. Integrated over the entire day, NA calculated from the 2006 and the 2007 NA patterns was 1 and 2 orders of magnitude, respectively, lower than the actual inte- 


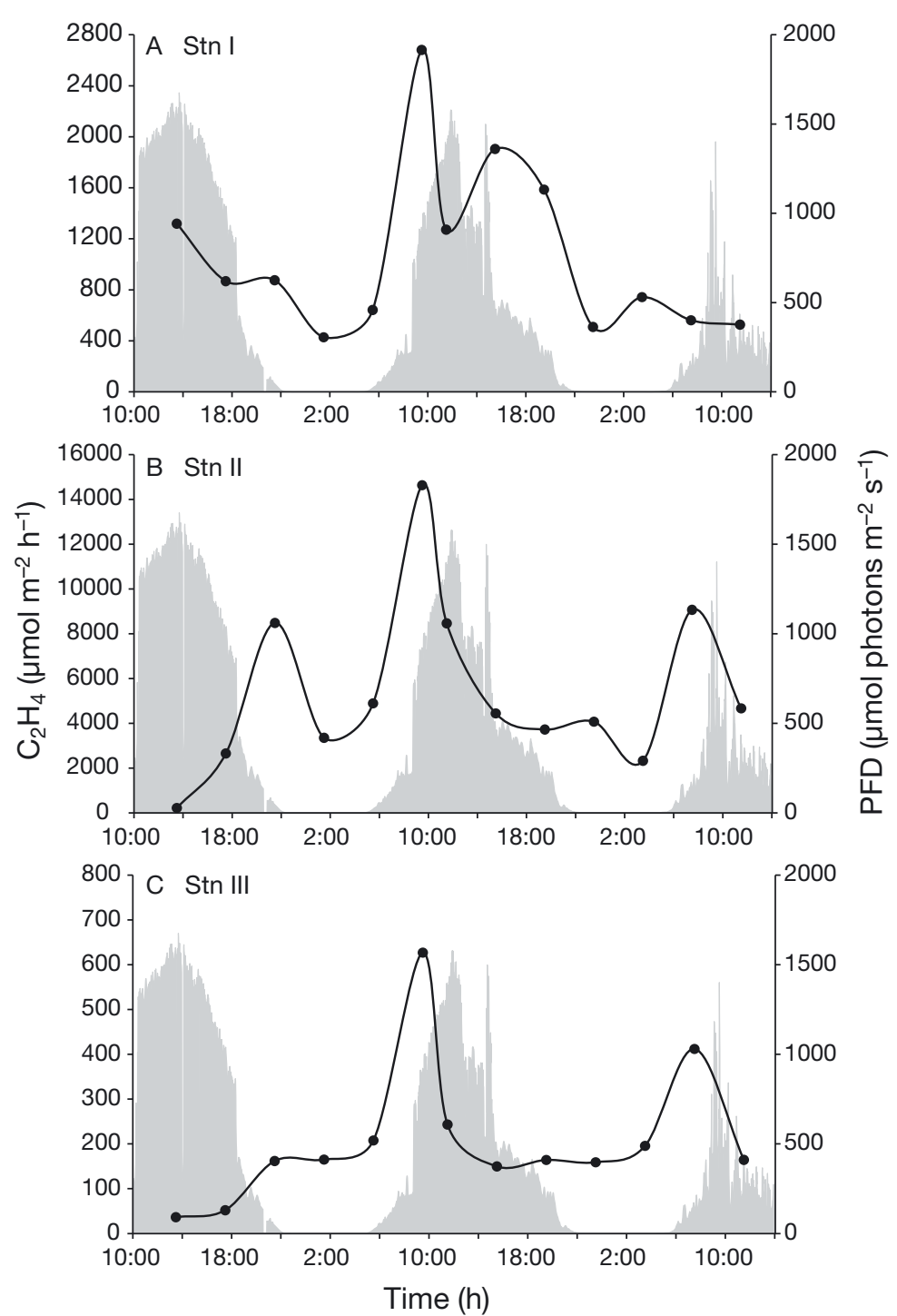

Fig. 2. Nitrogenase activity (NA: •), 24 h cycle as measured by acetylene reduction assay (ARA) in 2008 and the natural incident photon flux densities

(PFD) over the same period. Note different scales of the primary $y$-axis

The NA pattern of Stn III predicted from the light response curves obtained in 2007 (Fig. 3C) showed more similarity to the 2008 pattern than was seen between predicted and actual patterns for Stns I and II. However, in addition to the dominant peaks at sunset and sunrise predicted from 2007 data, 2 further peaks occurred during daytime in 2008. Based on this calculation, daytime NA was higher than nighttime activity. Moreover daily integrated NA rates for the calculated 2007 cycle were 1 order of magnitude lower than the actual rates measured in $2008\left(\sim 370 \mu \mathrm{mol} \mathrm{C}_{2} \mathrm{H}_{4}\right.$ $\mathrm{m}^{-2} \mathrm{~d}^{-1}$ in 2007 compared to $\sim 5000 \mu \mathrm{mol}$ $\mathrm{C}_{2} \mathrm{H}_{4} \mathrm{~m}^{-2} \mathrm{~d}^{-1}$ in 2008).

\section{Spatial variability in diazotrophic community composition}

An approximation of the community of potential diazotrophs at the 3 stations in 2008 was obtained from the 2008 clone libraries of nifH, by analyzing their sequence similarity to reference sequences in the BLASTn database (Fig. 4).

At Stn I, Cyanobacteria and Proteobacteria dominated the clone libraries with a contribution of $\sim 5 \%$ and $40 \%$, respectively. Most of the cyanobacterial sequences belonged to the Oscillatoriales $(\sim 91 \%)$ but some heterocystous Cyanobacteria (Nostocales) $(\sim 9 \%)$ were present in the clone libraries as well. The proteobacterial fraction was dominated by Alphaproteobacteria that contributed $\sim 70 \%$ to the proteobacterial nifH sequences. Deltaproteobacteria were also abundant $(\sim 27 \%)$ and Gammaproteobacteria ( $3 \%)$ were found

grated rates measured in $2008\left(3650 \mu \mathrm{mol} \mathrm{C}_{2} \mathrm{H}_{4} \mathrm{~m}^{-2} \mathrm{~d}^{-1}\right.$ for 2006 and $\sim 380 \mu \mathrm{mol} \mathrm{C}_{2} \mathrm{H}_{4} \mathrm{~m}^{-2} \mathrm{~d}^{-1}$ for $2007 \mathrm{com}$ pared to 25747 and $23321 \mu \mathrm{mol} \mathrm{C}_{2} \mathrm{H}_{4} \mathrm{~m}^{-2} \mathrm{~d}^{-1}$ on Days 1 \& 2, respectively, in 2008).

For Stn II only light response curves from 2006 were available for comparison. These showed a daily NA pattern (Fig. 3B) that was different from the one measured in 2008. In contrast to 2008 , where highest NA occurred at sunset and sunrise, the 2006 pattern showed NA confined to the night. Calculated daily integrated NA rates using data from 2006 were lower than the actual measurements in 2008. The calculated rate was $\sim 4500 \mu \mathrm{mol} \mathrm{C}_{2} \mathrm{H}_{4} \mathrm{~m}^{-2} \mathrm{~d}^{-1}$, compared with actual rates in 2008 of 147249 and $113188 \mu \mathrm{mol} \mathrm{C} \mathrm{C}_{2} \mathrm{H}_{4}$ $\mathrm{m}^{-2} \mathrm{~d}^{-1}$ on Days $1 \& 2$ respectively. in the clone libraries as well. In contrast to Stn I, hardly any Cyanobacteria-related sequences were found in the nifH clone libraries of Stn II. The few sequences that were found belonged to the Oscillatoriales. Proteobacterial sequences prevailed ( $66 \%$ of the sequences in the clone library). Gamma- and Deltaproteobacteria dominated with $\sim 53 \%$ and $38 \%$ of the proteobacterial sequences, respectively. Alpha- and Betaproteobacteria were also found $(\sim 7 \%$ and $2 \%$ of the clone library, respectively). Another group of potential diazotrophs at Stn II were the green sulfur bacteria (Chlorobi) with an overall contribution of $\sim 14 \%$ to the clone libraries. At Stn III Proteobacteria also dominated the nifH clone libraries with $\sim 80 \%$ of the sequences belonging to this group. Gamma- and Delta- 
Table 2. Details of nitrogenase activity (NA) measurements made in 2008, showing date and time, tidal height, light intensity, temperature at the mat surface and NA as measured by the acetylene reduction assay. NAP: Normal Amsterdam Level; PFD: photon flux density; nm: no measurement

\begin{tabular}{|c|c|c|c|c|c|c|c|c|c|}
\hline \multirow{2}{*}{$\begin{array}{l}\text { Date } \\
\text { (dd.mm.yy) }\end{array}$} & \multirow{2}{*}{$\begin{array}{l}\text { Time } \\
\text { (h) }\end{array}$} & \multirow{2}{*}{$\begin{array}{c}\text { Tidal height } \\
\text { (cm above } \\
\text { or below } \\
\text { NAP) }\end{array}$} & \multirow{2}{*}{$\begin{array}{c}\text { PFD } \\
(\mu \mathrm{mol} \\
\left.\mathrm{m}^{-2} \mathrm{~s}^{-1}\right)\end{array}$} & \multicolumn{3}{|c|}{ Temperature $\left({ }^{\circ} \mathrm{C}\right)$} & \multicolumn{3}{|c|}{$-\mathrm{NA}( \pm \mathrm{SD})\left(\mathrm{nmol} \mathrm{C} \mathrm{H}_{4} \mathrm{mg} \mathrm{chl} \mathrm{a}^{-1} \mathrm{~h}^{-1}\right)$} \\
\hline & & & & Stn I & Stn II & Stn III & Stn I & Stn II & Stn III \\
\hline 07.06 .08 & $23: 30$ & 20 & 0.5 & $\mathrm{~nm}$ & $\mathrm{~nm}$ & $\mathrm{~nm}$ & $59.3( \pm 40.0)$ & $1033.7( \pm 1440.9)$ & $1140.9( \pm 327.5)$ \\
\hline 08.06 .08 & $11: 30$ & 40 & 1307.8 & $\mathrm{~nm}$ & $\mathrm{~nm}$ & $\mathrm{~nm}$ & $5136.1( \pm 886.1)$ & $367.1( \pm 118.8)$ & $305.6( \pm 41.6)$ \\
\hline 08.06 .08 & $23: 30$ & -26 & 0.4 & 17.1 & 16.8 & 17.7 & $25.8( \pm 3.6)$ & $496.4( \pm 423.9)$ & $239.4( \pm 47.9)$ \\
\hline 09.06 .08 & $11: 30$ & -13 & 1344.5 & 21.5 & 23.1 & 21.5 & $3824.5( \pm 2611.8)$ & $371.4( \pm 376.6)$ & $692.6( \pm 164.0)$ \\
\hline 09.06 .08 & $23: 30$ & -81 & 0.2 & 19.3 & 17.6 & 18.8 & 31.4 & $58.3( \pm 3.1)$ & $675.6( \pm 42.1)$ \\
\hline 10.06 .08 & $11: 30$ & -75 & 1035.3 & 19.4 & 18.6 & 18.4 & $1381.5( \pm 956.9)$ & $565.9( \pm 100.5)$ & $226.6( \pm 193.6)$ \\
\hline 10.06 .08 & $23: 30$ & -126 & 0.6 & 16.5 & 16.1 & 15.8 & $289.5( \pm 221.5)$ & $30.6( \pm 18.2)$ & $165.1( \pm 36.9)$ \\
\hline 11.06 .08 & $11: 30$ & -116 & 1079.5 & 19.6 & 17.5 & 17.8 & $1775.8( \pm 1121.8)$ & $26.2( \pm 33.1)$ & $342.2( \pm 61.8)$ \\
\hline 11.06 .08 & $23: 30$ & -137 & 0.7 & 14.4 & 14.0 & 13.5 & $\mathrm{~nm}$ & $43.5( \pm 11.6)$ & $392.2( \pm 5.8)$ \\
\hline 12.06 .08 & $11: 30$ & -117 & 623.5 & 15.8 & 15.0 & 15.4 & $336.2( \pm 262.2)$ & $566.5( \pm 618.3)$ & $1775.0( \pm 147.9)$ \\
\hline 12.06 .08 & $23: 30$ & -108 & 0.5 & 13.6 & 13.6 & 13.5 & $128.0( \pm 92.8)$ & $25.9( \pm 16.4)$ & $788.0( \pm 21.0)$ \\
\hline 13.06 .08 & $11: 30$ & -82 & 1069.5 & 14.9 & 15.0 & 14.4 & $536.5( \pm 452.5)$ & $936.4( \pm 564.3)$ & $113.6( \pm 104.9)$ \\
\hline 13.06 .08 & $23: 30$ & -53 & 0.6 & 13.0 & 12.5 & 12.8 & $36.8( \pm 30.6)$ & $11.1( \pm 4.4)$ & $742.7( \pm 332.0)$ \\
\hline 14.06 .08 & $11: 30$ & -27 & 847.6 & 16.0 & 5.0 & 4.8 & $434.9( \pm 66.2)$ & $162.7( \pm 104.3)$ & $428.2( \pm 11.6)$ \\
\hline 14.06 .08 & $23: 30$ & 2 & 0.6 & 13.0 & 13.3 & 12.7 & $638.6( \pm 518.9)$ & $27.1( \pm 5.7)$ & $955.2( \pm 179.3)$ \\
\hline 15.06 .08 & $11: 30$ & 24 & 1363.7 & 14.8 & 14.8 & 14.8 & $548.2( \pm 55.5)$ & $463.3( \pm 50.5)$ & $1135.5( \pm 347.9)$ \\
\hline 15.06 .08 & $23: 30$ & 43 & 0.5 & 14.5 & 14.6 & 14.5 & $79.8( \pm 60.3)$ & $11.8( \pm 2.0)$ & $311.5( \pm 93.4)$ \\
\hline 16.06 .08 & $11: 30$ & 61 & 1265.7 & 14.5 & 14.5 & 14.5 & 322.8 & $443.2( \pm 186.3)$ & $357.2( \pm 152.5)$ \\
\hline 16.06 .08 & $23: 30$ & 70 & 0.1 & 13.1 & 13.3 & 13.2 & $114.9( \pm 150.2)$ & $10.4( \pm 4.7)$ & $93.9( \pm 65.7)$ \\
\hline 17.06 .08 & $11: 30$ & 86 & 1267.2 & 16.0 & 16.0 & 16.0 & $235.7( \pm 159.5)$ & $309.1( \pm 7.4)$ & $318.0( \pm 66.9)$ \\
\hline 17.06 .08 & $23: 30$ & 84 & 0.8 & 16.0 & 16.4 & 16.2 & $11.1( \pm 13.4)$ & $20.1( \pm 3.5)$ & $746.3( \pm 176.4)$ \\
\hline 18.06 .08 & $11: 30$ & 104 & 1173.1 & 18.5 & 18.0 & 16.8 & $259.3( \pm 6.3)$ & $265.9( \pm 69.6)$ & $88.8( \pm 33.8)$ \\
\hline 18.06 .08 & $23: 30$ & 89 & 0.4 & 16.7 & 16.3 & 15.9 & $46.4( \pm 40.7)$ & $38.8( \pm 3.7)$ & $663.6( \pm 9.8)$ \\
\hline 19.06 .08 & $11: 30$ & 112 & 295.0 & 20.1 & 18.9 & 18.7 & $186.0( \pm 53.7)$ & $370.1( \pm 231.4)$ & $106.4( \pm 3.2)$ \\
\hline
\end{tabular}

Table 3. One-way ANOVA of environmental parameters and nitrogenase activity (NA) at Stns I, II and III in 2008. PFD: photon flux density

\begin{tabular}{|lrrr|}
\hline \multirow{2}{*}{$\begin{array}{l}\text { Environmental } \\
\text { parameter }\end{array}$} & \multicolumn{3}{c}{ Explained variation in NA (p) } \\
\cline { 2 - 4 } & Stn I & Stn II & Stn III \\
\hline Tide & $4.5 \%(0.805)$ & $4.5 \%(0.935)$ & $0.3 \%(0.345)$ \\
PFD & $27.2 \%(0.006)$ & $11.9 \%(0.055)$ & $2.9 \%(0.562)$ \\
Temperature & $28.5 \%(0.007)$ & $0.4 \%(0.312)$ & $4.4 \%(0.743)$ \\
\end{tabular}

proteobacteria prevailed $(\sim 61 \%$ and $31 \%$ of the proteobacterial nifH sequences in the clone library, respectively) but alphaproteobacterial sequences were also found. Green sulfur bacteria also contributed to the clone libraries $(\sim 4 \%)$.

\section{Temporal variability in diazotrophic community composition}

The nifH gene pool of the Stns I \& II for the $3 \mathrm{yr}$ was compared (Fig. 4) while for Stn III only data for 2007 and 2008 were available. For the 3 stations we also compared the diversity predicted by the Chao1 diversity estimator (Table 4) and the overlap of OTUs found for the diazotrophic communities of each station in successive years (Table 5) at a 99\% similarity cut-off.

In 2006 half of the nifH sequences retrieved at Stn I belonged to Cyanobacteria, the majority was most closely related to the order of Oscillatoriales. As in 2008, Deltaproteobacteria represented a substantial fraction of the nifH gene pool. In contrast to 2008, Gammaproteobacteria were the predominant proteobacterial diazotrophs in 2006. In 2007, the cyanobacterial contribution to the nifH clone library was $<40 \%$ and, in contrast to both 2006 and 2008, dominated by Cyanobacteria most closely related to Chroococcales. Sequences belonging to Alpha-, Beta-, Gamma- and Deltaproteobacteria were found in 2007 and comprised more than half of the nifH clone libraries. Gammaproteobacterial nifH sequences were slightly more abundant than those clustering with the other subgroups. The nifH diversity at Stn I as predicted by the Chao1 diversity estimator was highest in 2006 and lowest in 2008. The similarity of the diazotrophic community composition between the years 


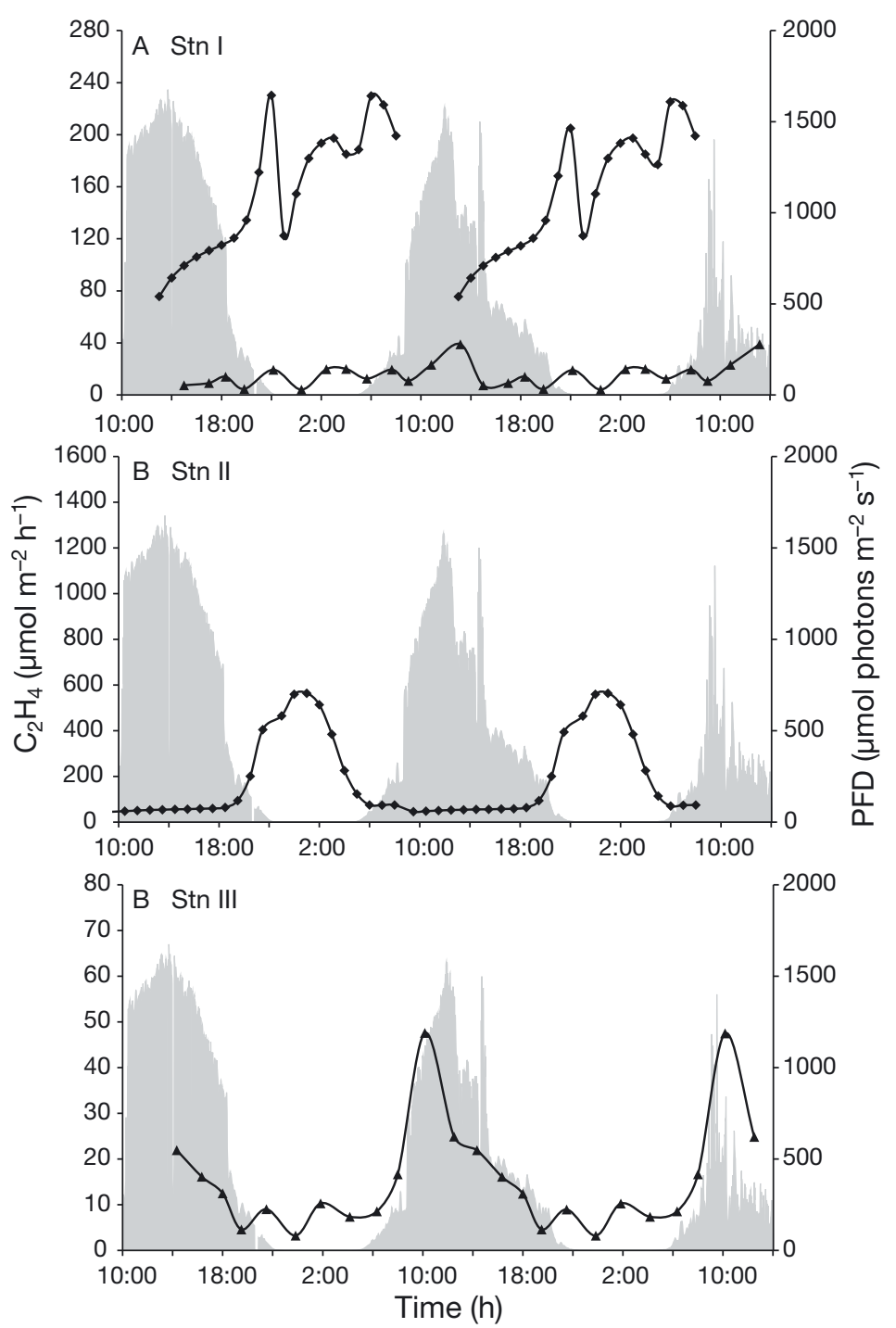

Fig. 3. Nitrogenase activity (NA), $24 \mathrm{~h}$ cycle as calculated on the basis of light response curves from $2006(\bullet)$ and $2007(\boldsymbol{\Delta})$ and the natural incident photon flux densities as recorded in 2008. Note different scales of the primary $y$-axis; they are 1 order of magnitude lower than those in Fig. 2 diversity was similar to each other but lower than in 2008. As for Stn I, the highest overlap of OTUs was found for the diazotrophic communities in 2007 and 2008, representing $\sim 11 \%$ and $14 \%$ of the sequences, respectively.

At Stn III, a clear prevalence of deltaproteobacterial nifH sequences was observed in 2007 whereas Gammaproteobacteria dominated in 2008. In 2007, only few sequences belonging to Alpha- and Gammaproteobacteria were present in the clone libraries. As in 2008, only a minor fraction of the nifH sequences belonged to Cyanobacteria. In 2007, all of these cyanobacterial nifH sequences clustered within the order of Chroococcales. The diazotrophic diversity predicted by Chao1 was slightly higher in 2008. Compared to the other stations, the number of shared OTUs in 2007 and 2008 was low, accounting for only $1 \%$ of the sequences.

Clustering analyses of the diazotrophic communities of all samples based on the presence of OTUs and the number of sequences belonging to these OTUs demonstrated that the temporal variability of the diazotrophic community was largest between 2006 and 2007 (Fig. 5).

\section{DISCUSSION}

\section{Spatial variability in nitrogenase activity and diazotrophic community composition}

In 2008, a morning peak of NA was the only feature common to all 3 stations. Higher rates of NA in the morning might have been favoured by an advantageous combination of increasing light intensities based on the number of shared OTUs was highest for 2007 and 2008: $12 \%$ of the sequences from 2007 were also found in 2008 while $\sim 40 \%$ of the sequences retrieved in 2008 were already known from 2007.

At Stn II, most nifH sequences belonged to Cyanobacteria in 2006 whereas hardly any cyanobacterial nifH could be retrieved in 2007 and 2008. Most of the cyanobacterial sequences found in 2006 clustered with Oscillatoriales. In 2006 and 2008, 25\% of the proteobacterial community belonged to the Deltaproteobacteria. They dominated the nifH clone library in 2007 whereas Gammaproteobacteria were dominant in 2008. The diversity based on the Chao1 estimator was highest for 2008. In 2006 and 2007, the estimated and low oxygen concentrations. If an evening peak of NA was detected as well, it was lower than the morning peak in all cases. The same pattern has also been observed in other cyanobacterial mats (Stal et al. 1984, Villbrandt et al. 1990). In other respects, all 3 mat types showed differences in NA and their diazotrophic community compositions. The different patterns of NA in each of the mat types can most likely be attributed to the dissimilar diazotrophic communities at the 3 stations. As for the daily pattern of NA, the clone libraries approximating the diazotrophic communities of Stns II and III were more similar to each other than either of these was to Stn I. This was confirmed by the comparison of common OTUs. We used a $99 \%$ similarity cut-off 
2006
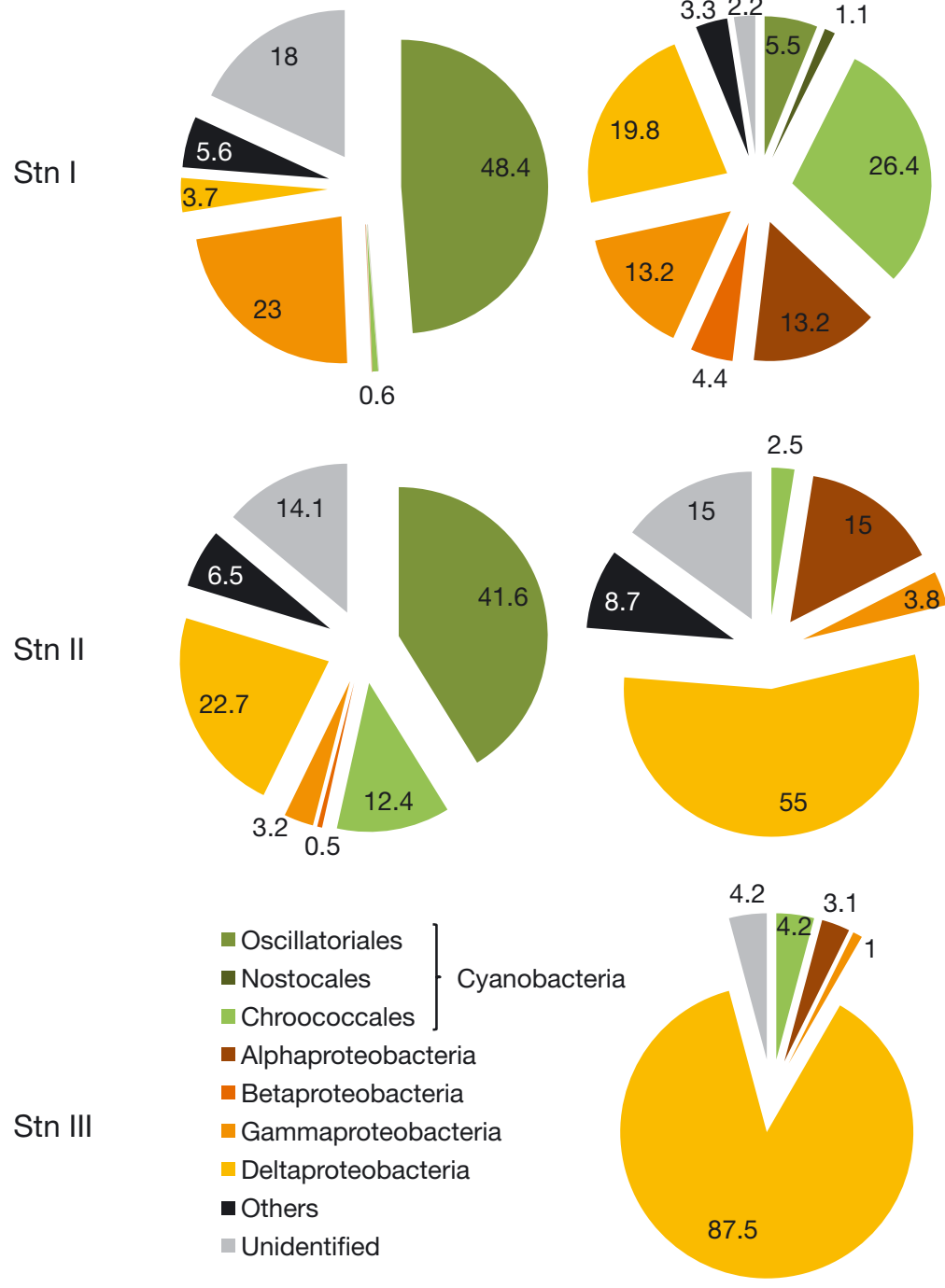

2007

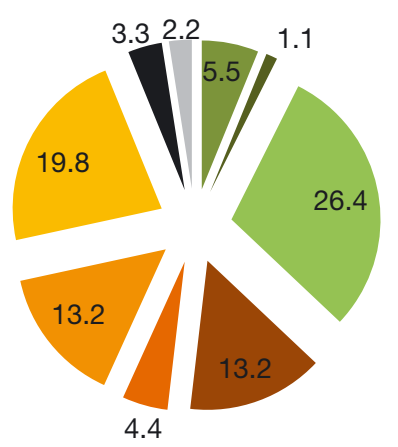

2.5
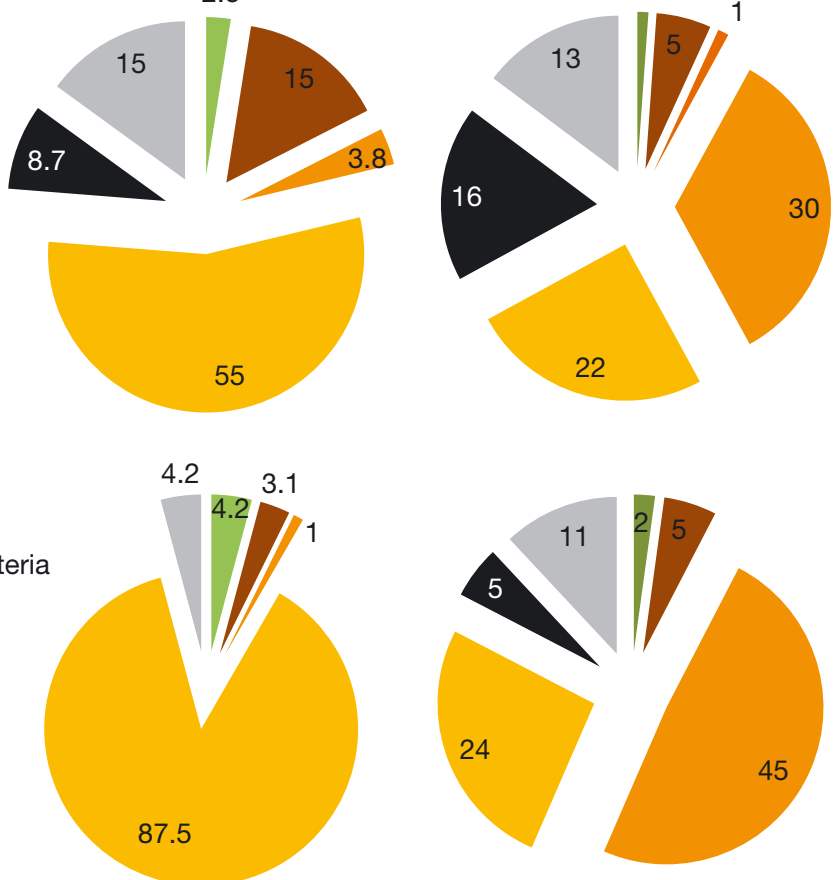

Fig. 4. Relative contributions of major bacterial groups to the nifH clone libraries for Stns I, II and III in 2006, 2007 and 2008. Relative contributions (\%) are given within or next to each pie segment (only values $\geq 0.5 \%$ are shown)

Table 4. Number of sequences per clone library, number of operational taxonomic units (OTUs) at $99 \%$ similarity and Chao1 diversity estimates based on nifH clone libraries

\begin{tabular}{|lccc|}
\hline & $\begin{array}{c}\text { Number of } \\
\text { sequences }\end{array}$ & $\begin{array}{c}\text { Number of } \\
\text { OTUs }\end{array}$ & $\begin{array}{c}\text { Chao1 diversity } \\
\text { (OTUs) }\end{array}$ \\
\hline Stn I & 127 & 60 & 147 \\
2006 & 92 & 45 & 111 \\
2007 & 93 & 37 & 54 \\
2008 & & & \\
Stn II & 154 & 55 & 72 \\
2006 & 80 & 58 & 277 \\
2007 & 88 & 64 & 150 \\
2008 & & & 177 \\
Stn III & 96 & 34 & \\
2007 & 92 & 62 & \\
2008 & & & \\
\hline
\end{tabular}

in order not to overlook the microdiversity fraction observed in the majority of marine microbial communities (Acinas et al. 2004, Klepac-Ceraj et al. 2004, Haverkamp et al. 2008). At this similarity level, the clone libraries of Stns II and III shared more OTUs than either of these stations shared with Stn I. Due to their location in the intertidal zone, Stns II and III were more often covered by seawater than Stn I and this might have resulted in more similar community composition. The salinity of interstitial water and desiccation time have been proposed to be the main environmental variables determining community composition of the mats on Schiermonnikoog (Dijkman et al. 2010). However, environmental conditions other than salinity and desiccation time might also have influenced the diazo- 
Table 5. Diversity comparison of Stns I, II and III in 2006, 2007 and 2008 based on shared operational taxonomic units (OTUs) at $99 \%$ similarity. The two values in the 3rd and 5th colums represet the percentages shared OTUs in the 2 years that are compared. These percentages depend on the total number of OTUs in these years

\begin{tabular}{|lcccc|}
\hline & $\begin{array}{c}\text { Shared } \\
\text { OTUs (no.) }\end{array}$ & $\begin{array}{c}\text { Shared } \\
\text { OTUs (\%) }\end{array}$ & \multicolumn{2}{c|}{$\begin{array}{c}\text { Sequences in shared } \\
\text { OTUs (no.) }\end{array}$} \\
OTUs (\%)
\end{tabular}

trophic community. The different locations of the mats within the intertidal area of the sandy North Sea beach also result in differences in water availability, temperature, sedimentation patterns, oxygen concentration and oxygen penetration depth. The reason for the almost complete lack of cyanobacterial nifH at Stns II and III is not clear. The filamentous non-heterocystous Cyanobacteria observed at these 2 stations may not have been diazotrophic species. However, it is known that discrepancies exist between clone libraries based on nifH and those based on their reverse transcripts (e.g. Hewson et al. 2007, Man-Aharonovich et al. 2007, Severin et al. 2010). Therefore, it is possible that there was nifH expression by Cyanobacteria even though the cyanobacterial nifH copy number was low.

\section{Factors influencing nitrogenase activity}

There were differences in both the daily pattern and integrated rates of NA between the 2 consecutive days when measurements were made. Because in phototrophic diazotrophs light is a direct or indirect source of energy for nitrogenase (e.g. Bebout et al. 1987), we conjectured that the variation of light caused the difference in NA. Moreover, low light intensity may limit growth and metabolic activity of phototrophs but also of chemotrophs, that depend on the products of photosynthesis, for instance to satisfy the demand of reducing equivalents for $\mathrm{N}_{2}$ fixation (Bebout et al. 1993). However, although integrated daily light on Day 2 of the NA measurement was only $34 \%$ of that on Day 1 , integrated NA decreased only slightly, probably because the incident light intensities were still saturating for NA. The daily integrated NA might have been independent of the daily integrated incident photon flux. This was shown for mats at Stns I and II in 2006 (Severin \& Stal 2008). It is possible that during a day with a high daily photon flux more storage carbohydrate accumulates, which can then be used during a subsequent day with less light so that overall NA is maintained. If breakdown of stored carbohydrates was the main energy source of NA, this might also explain a less variable daily pattern compared to scenarios where light-mediated processes (i.e. photosynthesis) serve as the main energy source for NA.

The impact of temperature, light intensity and tidal cycle on NA in 2008 was tested in order to elucidate whether these factors might control NA in the 3 mat types. If phototrophs were responsible for $\mathrm{N}_{2}$ fixation, light would be an important controlling factor. In line with this, a significant impact of variations in light intensities on NA was found for the station that was shown to harbour many diazotrophic Cyanobacteria. Variations in light intensity also influenced NA at Stn II although we hardly found any diazotrophic Cyanobacteria at this station. However, anoxygenic phototrophic diazotrophs might have been important at this station as indicated by the gammaproteobacterial nifH sequences in our clone libraries. Moreover, nondiazotrophic phototrophs could be responsible for supplying reductant that is then used by diazotrophs and, thus, light intensity might still play a role in controlling NA. On the other hand, diazotrophic Gammaproteobacteria were also found at Stn III, where light appeared to have no effect on NA. The reason for this is not clear. At both Stns II and III, most of these Gammaproteobacteria were phototrophs (purple sulfur bacteria). Nevertheless, we expect that also chemotrophic diazotrophs depend indirectly on light, because in order to be able to fix $\mathrm{N}_{2}$ they depend on products of photosynthesis. Obviously, other factors may also have played a role, among which temperature might have been important. It is known that the rate of metabolic processes vary with temperature according to the temperature quotient $\mathrm{Q}_{10}$ which is generally close to 2 . This means that the rate of NA might double or halve in response to a rise or decrease of the temperature by $10^{\circ} \mathrm{C}$. The difference in temperature recorded at the time of sampling on each of the mat surfaces was sufficiently large to cause such effect. However, the rate of NA will be controlled by a variety of factors and different organisms may have different temperature optima. The tidal cycle, and therefore the coverage with seawater, might have exerted an important influence on NA as well. The tidal position, which results in differences in seawater coverage and therefore desiccation frequency, has been demonstrated to shape community structure, diversity and richness of microbial mats situated in an intertidal area (Rothrock 


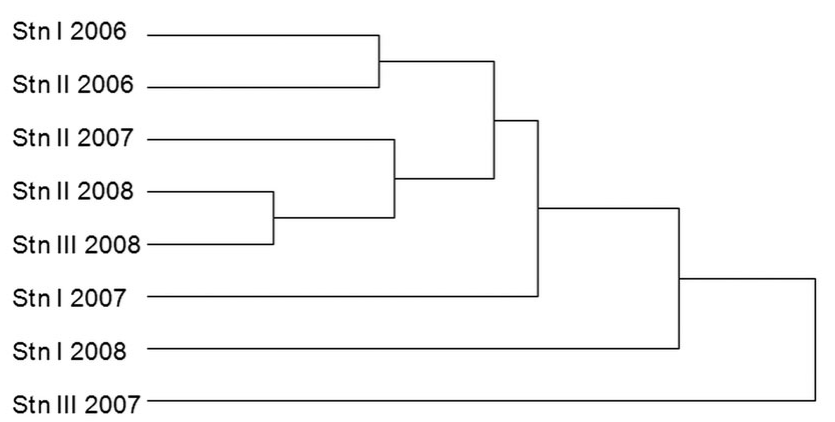

Fig. 5. Clustering based on the presence of operational taxonomic units (OTUs) and the number of sequences belonging to these OTUs at a $99 \%$ nucleotide sequence similarity level for Stns I, II and III in 2006, 2007 and 2008

\& Garcia-Pichel 2005), but we excluded this factor as one controlling NA in the mats investigated because only Stn II became inundated at high tide during the sampling in 2008.

\section{Temporal variability in nitrogenase activity and diazotrophic community composition}

Besides the differences caused by the position of the microbial mats along the intertidal gradient, the change in beach morphology during the 3 yr study period might have had an effect on the microbial mats. Annual changes in the total bacterial and diazotrophic community compositions have been demonstrated for 2006 and 2007 (Severin et al. 2010). At Stns II and III, there was little overlap between the diazotrophic communities in 2007 and 2008. However, when comparing the diazotrophic communities of Stns I and II, it became clear that the largest shift happened between 2006 and 2007. The shift in community composition from one year to the next was most likely caused by morphological changes of the beach area, which was visible as an increase of marsh vegetation from 2006 to 2008, as well as by differences in climatic conditions between these years, especially with respect to temperature, light and rainfall. The spring preceding the sampling in 2006 was sunny but wet and allowed strong mat development. Springs in 2007 and 2008 were warm and dry and this may have contributed to the development of a diazotrophic community dissimilar from 2006; while the similar climate conditions produced less variation between those $2 \mathrm{yr}$. The extent to which the sampling area was covered by salt marsh vegetation was also more different between 2006 and 2007 than between 2007 and 2008.

Since the characteristics of NA can be derived from the light response curves (Staal et al. 2002), we calculated the daily cycle of NA based on the light response curves generated in 2006 and 2007 and the light intensities measured in 2008. By this means, we compared the characteristics of NA for each mat in 3 subsequent years while omitting differences in light intensity as one of the factors likely to cause differences in the daily NA pattern. If the 2008 mats exhibited NA activity characteristics similar to the 2006 and 2007 mats, applying the light response curves from 2006 and 2007 to the light intensities recorded in 2008 would result in similar daily NA patterns for the 3 yr. However, daily patterns of NA in the $3 \mathrm{yr}$ were different both with respect to total activity as well as to the daily patterns. This is in line with the shift in diazotrophic community composition and confirms our hypothesis that differences in the diazotrophic community composition also influence daily NA patterns. One might expect that different diazotrophs adapt in different ways to environmental conditions and therefore exhibit different daily patterns of NA, although experiments showing that this is indeed the case have not been reported in the literature. The lower daily integrated NA rates calculated for Stn I in 2007 and Stn II in 2008 as compared to the other years at these stations are also attributed to the shift in diazotrophic community composition. In both cases, a decrease in the contribution of Oscillatoriales to the diazotrophic community might have caused the lower NA rates. An increase of nifH sequences related to Oscillatoriales at Stn I in 2008 coincided with an increase in daily integrated NA rates and supports this hypothesis.

Studies that follow community composition and metabolic activity of microbial mats over the course of several years are rare. There are, however, microbial mats located in the intertidal zone of Bird Shoal island (Rachel Carson National Estuarine Research Reserve, North Carolina, USA), where the diazotrophic community and NA have been extensively studied during the last decade (e.g. Zehr et al. 1995, Paerl et al. 1996, Steppe \& Paerl 2002, 2005). These studies revealed marked seasonal changes in NA pattern and rate, most likely due to changes in the composition of the diazotrophic community. Earlier studies conducted in 1992 and 1993 showed a shift from cyanobacterial diazotrophs in summer to chemotrophic diazotrophs in winter, which was accompanied by high NA rates and predominant nighttime activity during summer and low NA rates and predominant daytime activity during winter (Zehr et al. 1995, Paerl et al. 1996). In the period between 1997 and 1999, these seasonal changes in daily NA patterns were again apparent but were less obvious at times and accompanied by a third pattern of high sunrise NA in summer. The diazotrophic community included the same major groups in all seasons and years (Steppe \& Paerl 2002, 2005). In contrast to the mats investigated by us, the Bird Shoal mats did appar- 
ently not experience the same large changes in environmental conditions (light, temperature, tidal range) from year to year and therefore might have been more stable with respect to community composition and NA.

Combining the analysis of the diazotrophic community composition with detailed NA measurements allows us to draw the following conclusions. (1) Spatial heterogeneity, i.e, the different positions of the microbial mats along the intertidal gradient, as well as temporal changes in external factors such as beach morphology and climate provide a likely explanation for the dissimilar diazotrophic communities in the 3 mat types and for changes that occurred over the 3 yr study. (2) These differences are also conjectured to be the cause of the observed differences of daily nitrogenase rates and patterns. (3) Light was the main driver behind the short-term variability of NA, either as a direct energy supply for nitrogenase in the phototrophs or indirectly by providing photosynthate to chemotrophic diazotrophs.

Acknowledgements. This work was financially supported by the Netherlands Research Council (NWO) contract ALW 815.01.003 and the Schure-Beijerinck-Popping fund (KNAW). This is publication 4890 of the Netherlands Institute of Ecology (NIOO-KNAW).

\section{LITERATURE CITED}

Acinas SG, Klepac-Ceraj V, Hunt DE, Pharino C, Ceraj I, Distel DL, Polz MF (2004) Fine-scale phylogenetic architecture of a complex bacterial community. Nature 430: 551-554

Bebout BM, Paerl HW, Crocker KM, Prufert LE (1987) Diel interactions of oxygenic photosynthesis and $\mathrm{N}_{2}$ fixation (acetylene reduction) in a marine microbial mat community. Appl Environ Microbiol 53:2353-2362

Bebout BM, Fitzpatrick MW, Paerl HW (1993) Identification of the sources of energy for nitrogen fixation and physiological characterization of nitrogen-fixing members of a marine microbial mat community. Appl Environ Microbiol 59:1495-1503

Ben-Porath J, Zehr JP (1994) Detection and characterization of cyanobacterial nifH genes. Appl Environ Microbiol 60:880-887

Dijkman NA, Boscher HTS, Stal LJ, Kromkamp JC (2010) Composition and heterogeneity of the microbial community in a coastal microbial mat as revealed by the analysis of pigments and phospholipid-derived fatty acids. J Sea Res 63:62-70

- Hardy RWF, Holsten RD, Jackson EK, Burns RC (1968) Acetylene-ethylene assay for $\mathrm{N}_{2}$ fixation: laboratory and field evaluation. Plant Physiol 43:1185-1207

Haverkamp T, Acinas SG, Doeleman M, Stomp M and others (2008) Diversity and phylogeny of Baltic Sea picocyanobacteria inferred from their ITS and phycobiliprotein operons. Environ Microbiol 10:174-188

- Hewson I, Moisander PH, Morrison AE, Zehr JP (2007) Diazotrophic bacterioplankton in a coral reef lagoon: phylogeny, diel nitrogenase expression and response to phosphate enrichment. ISME J 1:78-91
Jørgensen BB, Revsbech NP, Cohen Y (1983) Photosynthesis and structure of benthic microbial mats: microelectrode and SEM studies of four cyanobacterial communities. Limnol Oceanogr 28:1075-1093

> Joye SB, Paerl HW (1994) Nitrogen cycling in microbial mats: rates and patterns of denitrification and nitrogen fixation. Mar Biol 119:285-295

Klepac-Ceraj V, Bahr M, Crump BC, Teske AP, Hobbie JE, Polz MF (2004) High overall diversity and dominance of microdiverse relationships in salt marsh sulphate-reducing bacteria. Environ Microbiol 6:686-698

Krumbein WE, Cohen Y, Shilo M (1977) Solar Lake (Sinai). 4. Stromatolitic cyanobacterial mats. Limnol Oceanogr 22: 635-656

Man-Aharonovich D, Kress N, Bar Zeev E, Berman-Frank I, Beja O (2007) Molecular ecology of nifH genes and transcripts in the eastern Mediterranean Sea. Environ Microbiol 9:2354-2363

Olson JB, Litaker RW, Paerl HW (1999) Ubiquity of heterotrophic diazotrophs in marine microbial mats. Aquat Microb Ecol 19:29-36

Paerl HW (1990) Physiological ecology and regulation of $\mathrm{N}_{2}$ fixation in natural waters. Adv Microb Ecol 11:305-344

Paerl HW, Fitzpatrick M, Bebout BM (1996) Seasonal nitrogen fixation dynamics in a marine microbial mat: potential roles of cyanobacteria and microheterotrophs. Limnol Oceanogr 41:419-427

Revsbech NP, Jørgensen BB, Blackburn TH, Cohen Y (1983) Microelectrode studies of the photosynthesis and $\mathrm{O}_{2}, \mathrm{H}_{2} \mathrm{~S}$ and $\mathrm{pH}$ profiles of a microbial mat. Limnol Oceanogr 28: 1062-1074

$>$ Rothrock MJ, Garcia-Pichel F (2005) Microbial diversity of benthic mats along a tidal desiccation gradient. Environ Microbiol 7:593-601

Schloss PD, Handelsman J (2005) Introducing DOTUR, a computer program for defining operational taxonomic units and estimating species richness. Appl Environ Microbiol 71:1501-1506

- Schloss PD, Handelsman J (2006) Introducing SONS, a tool for operational taxonomic unit-based comparisons of microbial community memberships and structures. Appl Environ Microbiol 72:6773-6779

> Severin I, Stal LJ (2008) Light dependency of nitrogen fixation in a coastal cyanobacterial mat. ISME J 2:1077-1088

Severin I, Stal LJ (2010) NifH expression by five groups of phototrophs compared with nitrogenase activity in coastal microbial mats. FEMS Microbiol Ecol 73:55-67

Severin I, Acinas S, Stal LJ (2010) Diversity of nitrogen-fixing bacteria in cyanobacterial mats. FEMS Microbiol Ecol 73: 514-525

Staal M, te Lintel-Hekkert S, Harren F, Stal LJ (2001) Nitrogenase activity in cyanobacteria measured by the acetylene reduction assay: a comparison between batch incubation and on-line monitoring. Environ Microbiol 3:343-351

Staal M, te Lintel-Hekkert S, Herman P, Stal LJ (2002) Comparison of models describing light dependence of $\mathrm{N}_{2}$ fixation in heterocystous Cyanobacteria. Appl Environ Microbiol 68:4679-4683

> Stal LJ (1988) Nitrogen fixation in microbial mats. Methods Enzymol 167:474-484

> Stal LJ, Grossberger S, Krumbein WE (1984) Nitrogen fixation associated with the cyanobacterial mat of a marine laminated microbial ecosystem. Mar Biol 82:217-224

> Steppe TF, Paerl HW (2002) Potential $\mathrm{N}_{2}$ fixation by sulfatereducing bacteria in a marine intertidal microbial mat. Aquat Microb Ecol 28:1-12

Steppe TF, Paerl HW (2005) Nitrogenase activity and nifH 
expression in a marine intertidal microbial mat. Microb Ecol 49:315-324

van Gemerden H (1993) Microbial mats: a joint venture. Mar Geol 113:3-25

> Villbrandt M, Stal LJ, Krumbein WE (1990) Interactions between nitrogen fixation and oxygenic photosynthesis in a marine cyanobacterial mat. FEMS Microbiol Ecol 74: 59-72

Zani S, Mellon MT, Collier JL, Zehr JP (2000) Expression of nifH genes in natural microbial assemblages in Lake

Editorial responsibility: Ronald Kiene,

Mobile, Alabama, USA
George, New York, detected by reverse transcriptase PCR. Appl Environ Microbiol 66:3119-3124

Zehr JP, McReynolds LA (1989) Use of degenerate oligonucleotides for amplification of the nifH gene from the marine cyanobacterium Trichodesmium thiebautii. Appl Environ Microbiol 55:2522-2526

Zehr JP, Mellon M, Braun S, Litaker W and others (1995) Diversity of heterotrophic nitrogen fixation genes in a marine cyanobacterial mat. Appl Environ Microbiol 61: 2527-2532

Submitted: December 9, 2009; Accepted: August 4, 2010 Proofs received from author(s): October 11, 2010 